\title{
EFFECTS OF STEROID AND NONSTEROID METABOLITES ON ENZYME CONFORMATION AND PYRIDOXAL PHOSPHATE BINDING*
}

\author{
Merle Mason, Jonathan Ford, and Helen L.C. Wu \\ Department of Biological Chemistry \\ The University of Michigan \\ Ann Arbor, Mich.
}

An understanding of the factors that influence the binding of pyridoxal phosphate (PLP) to the various tissue constituents is of major importance for an understanding of the metabolism, distribution and function of that coenzyme in mammalian systems. The main objectives of this paper are to review some studies pertaining to PLP binding and to present some of our more recent results that seem to bear on their biological relevance.

Our studies of PLP binding began with the discovery in 1957 that the kynurenine transaminase in freshly-prepared rat kidney homogenates was inactivated rapidly during incubation at 37 degrees $C$. and that added PLP restored the activity. ${ }^{1}$ We concluded that the inactivation reflected the loss of PLP from the enzyme and that factors which influenced the rate of loss did so by influencing the binding of PLP. Thus it was found that the dissociation was accelerated by lowering the $\mathrm{pH}$ and by increasing the concentration of inorganic phosphate ( $\mathbf{P i})$ in the incubation medium. $\alpha$-Ketoglutarate, one of the substrates, effectively prevented the dissociation when present at substrate levels.

Similar actions of $\mathbf{P i}$ were subsequently observed with other pyridoxal enzymes. $^{2-4}$ Scardi and associates ${ }^{2}$ reported that $\mathrm{Pi}$ promoted the dissociation of the coenzyme from glutamate-aspartate transaminase but only after it was converted to pyridoxamine phosphate by reaction with an amino acid substrate. The relatively greater binding stability of the pyridoxal form is usually attributed to the binding of the aldehyde group via a Schiff base linkage to an $\epsilon$-amino group of the apoenzyme. ${ }^{5}$ Transamination with the amino acid substrate breaks this linkage by converting the PLP to pyridoxamine phosphate. ${ }^{6}$ Presumably the $\mathrm{Pi}$ then displaces the ester phosphate group of the coenzyme from a cationic binding site of the apoenzyme, allowing ready dissociation.

The stabilization of PLP binding by $\alpha$-ketoglutarate, first observed in our studies of kynurenine transaminase, is thus probably characteristic of the transaminases. In addition, several pyridoxal enzymes which exhibit transaminase activity only as a minor function are activated and inactivated in a similar way. Novogrodsky and Meister $^{7}$ found that bacterial aspartate $\beta$-decarboxylase was inactivated by incubation with various L-amino acids and that the inactivation was prevented by analogous $\alpha$-keto acids and was reversed by PLP. Enzymic and spectrophotometric studies indicated that the inactivation was due to the formation of pyridoxamine phosphate by transamination, followed by dissociation of that coenzyme from the apodecarboxylase. A similar action of amino acid and keto acid substrates was observed by Schirch and Jenkins ${ }^{8}$ with serine transhydroxymethylase. That enzyme underwent transamination of the enzyme-bound PLP with D-alanine to yield pyridoxamine phosphate, the apoenzyme, and pyruvate. These studies emphasize the much greater binding stability of PLP as compared with pyridoxamine phosphate. However, the PLP can be removed from

\footnotetext{
- The investigations reported for the first time in this article were supported by PHS Research Grant No. 2294 from the National Institute of Arthritis and Metabolic Diseases.
} 
some enzymes without conversion to pyridoxamine phosphate. Its removal from phosphorylase is favored by the presence of cysteine, ${ }^{9}$ which binds it firmly as the thiazolidine, and by agents that disturb enzyme conformation. ${ }^{10}$

Since the activating and protective effects of $\alpha$-keto acids derive at least partly from their ability to maintain the coenzyme in the more stably-bound aldehyde form, it is to be expected that carboxylic acid analogs lacking the carbonyl group would not exhibit these actions and would perhaps antagonize them. Mason ${ }^{11}$ reported that certain monocarboxylic and dicarboxylic acids were powerful competitive inhibitors of kynurenine transaminase and that those that are analogs of the best keto acid substrates were the strongest inhibitors. To account for an unexpected variation in the effectiveness of the dicarboxylic acids with both chain-length and $\mathrm{pH}$, the author suggested that those acids, and presumably the analogous keto acids, were bound to the enzyme by both carboxylate groups at low $\mathrm{pH}$ values but were bound by only one carboxylate group at high $\mathrm{pH}$ values. Somewhat similar findings with highly-purified glutamateaspartate transaminase ${ }^{12}$ led Jenkins and $D^{\prime}$ Ari $^{13}$ to test and to verify the above hypothesis with that enzyme.

An interesting feature of the reaction of dicarboxylic acids with glutamateaspartate transaminase is that it results in changes in the spectrum of the bound PLP. ${ }^{13}$ Although these spectral changes indicate structural changes in the coenzyme or changes in its relation to the apoenzyme, no evidence concerning its effects on coenzyme binding has been presented. That such effects may occur is suggested by a stabilizing action of various carboxylic acids on coenzyme binding to kynurenine transaminase and tyrosine transaminase. ${ }^{14}$ Further studies are required, however, to determine if such actions occur with homogeneous enzyme preparations.

In an extension of their studies of the action of organic acids, ${ }^{11}$ Mason and Gullekson found that the sulfate esters of estradiol, estrone, and diethylstilbestrol inhibited that enzyme, apparently by interfering with the binding of PLP. ${ }^{15,16}$ The estrogen sulfates also retarded the irreversible enzyme inactivation caused by incubation at 37 degrees or by treatment with chymotrypsin. Pyridoxal phosphate also stabilized the enzyme, an action that now appears common for the pyridoxal enzymes. Steroid conjugates resembled the carboxylic acids in their ability to retard PLP dissociation ${ }^{14}$ but were effective at much lower concentrations.

The authors suggested ${ }^{16}$ that these various actions, which occur at very low levels of steroid sulfates in vitro, might also occur at the low levels of steroid conjugates that exist in the tissues. It was pointed out that the observed interactions might represent prototypes of similar interactions with other pyridoxal enzymes and possibly with other types of enzymes and cofactors. Subsequent studies indicated similar inhibitory effects with cysteine sulfinic decarboxylase, ${ }^{17}$ dopa decarboxylase, ${ }^{17}$-hydroxytryptophan decarboxylase, ${ }^{17}$ serine transhydroxymethylase, ${ }^{14,17}$ tyrosine transaminase, ${ }^{14}$ glutamate-aspartate transaminase, ${ }^{18}$ phosphorylase $a,{ }^{15}$ and phosphorylase $b .^{19}$ The effects of the conjugates on enzymes that do not require PLP have received little study. ${ }^{17}$ The estrogen sulfates did not inhibit the proteolysis of casein by chymotrypsin or trypsin. ${ }^{16,20}$ They did inhibit tryptophan pyrrolase, apparently by interfering with the binding of its heme cofactor. ${ }^{21}$ Glutamate dehydrogenase, previously reported to be inhibited by free steroids, ${ }^{22}$ is inhibited by certain steroid sulfates and activated by others. ${ }^{23}$

The ability of steroid conjugates to interfere with PLP binding has been attributed $^{16,18}$ to competitive displacement, presumably involving the sites that 
bind the ester phosphate group. Insight into the functional role of that group was provided by Wada and Snell. ${ }^{24}$ They reported that resolved glutamic-aspartic transaminase also exhibited pyridoxamine-oxaloacetic transaminase activity. A similar enzyme from rabbit liver was competitively inhibited by PLP and required $\mathbf{P i}$. The authors suggested that pyridoxamine and $\mathbf{P i}$ bind the sites of an apoenzyme that normally bind the analogous groups of PLP. The activating effect of Pi was attributed to an effect on enzyme conformation. Using a similar enzyme from rat kidney, Wu and Mason found that diethylstilbestrol diphosphate and PLP competitively inhibited the activation by $\mathbf{P i} .{ }^{25}$

The studies of Wada and Snell indicate that the ester phosphate group of PLP serves a function other than simply helping to bind the coenzyme to a specific site. Another enzyme in which Pi seems to serve as a substitute for the ester phosphate group of a coenzyme is the microsomal $\Delta^{4}$-3-ketosteroid reductase of rat liver, which requires NADP but can use NAD if Pi is also present. ${ }^{26}$ Wu and Mason ${ }^{27}$ studied testosterone sulfate as a potential inhibitor of that enzyme in the presence of NAD and $\mathrm{Pi}$. Instead of inhibiting the reductase, the conjugate served effectively as a substrate. Diethylstilbestrol diphosphate did not inhibit the activation with $\mathrm{Pi}$ at levels as high as $10^{-4} \mathrm{M} .^{28}$

Ford and Mason ${ }^{19}$ reported that anionic steroids reversibly altered the binding of PLP to phosphorylase $b$ (recrystallized 4-8 times), as shown by spectral changes, and increased the reactivity of the protein sulfhydryl groups. These actions were interpreted as reflecting increased exposure of "buried" sulfhydryl groups and PLP residues, implicating conformational changes in the protein. The rate of both changes was strongly influenced by the type of buffer used. The "buffers" tested were glycolytic intermediates and other known effectors of phosphoxylase $b$ activity. The spectral changes also correlated well with the rate of decrease of enzyme activity resulting from exposure to the conjugate, the rate being faster in buffers that promoted rapid spectral shifts.

The buffers that promoted the various changes in the presence of conjugates did not cause them in their absence but did cause increased formation of the tetrameric form of the enzyme. Glucose-6-phosphate, which retarded these changes, stabilized the dimeric form. It appears, therefore, that the conjugates can act either in cooperation with or in antagonism to the nonsteroid effectors to influence enzyme conformation and the accompanying changes in coenzyme binding, in the tendency to aggregate, and in enzyme activity and stability.

Additional studies of other highly-purified pyridoxal enzymes will be required in order to determine whether the effects of the conjugates on phosphorylase $b$ are typical. At present there are ample indications that the actions of the conjugates with various pyridoxal enzymes are associated with the actions of nonsteroid effectors that are fairly specific for each type of enzyme. This element of specificity suggests that conjugates may act, in vitro at least, in concert with appropriate nonsteroid effectors to promote the transfer of PLP from one apoenzyme to another. FIGURE 1 shows evidence of such action. Partially-purified tyrosine apotransaminase was activated by the addition of phosphorylase $b$ in the presence of 3-phosphoglycerate and diethylstilbestrol disulfate but not if the 3-phosphoglycerate was replaced by glucose-6-phosphate. Since the former but not the latter buffer permitted the changes in PLP binding to phosphorylase $b,{ }^{19}$ it would appear that those changes are crucial in the transfer of the PLP to the apotransaminase under the conditions studied. As expected, phosphorylase $b$ that had been treated with borohydride ${ }^{29}$ to reduce the potential aldehyde group of the bound PLP was unable to activate the apotransaminase. 


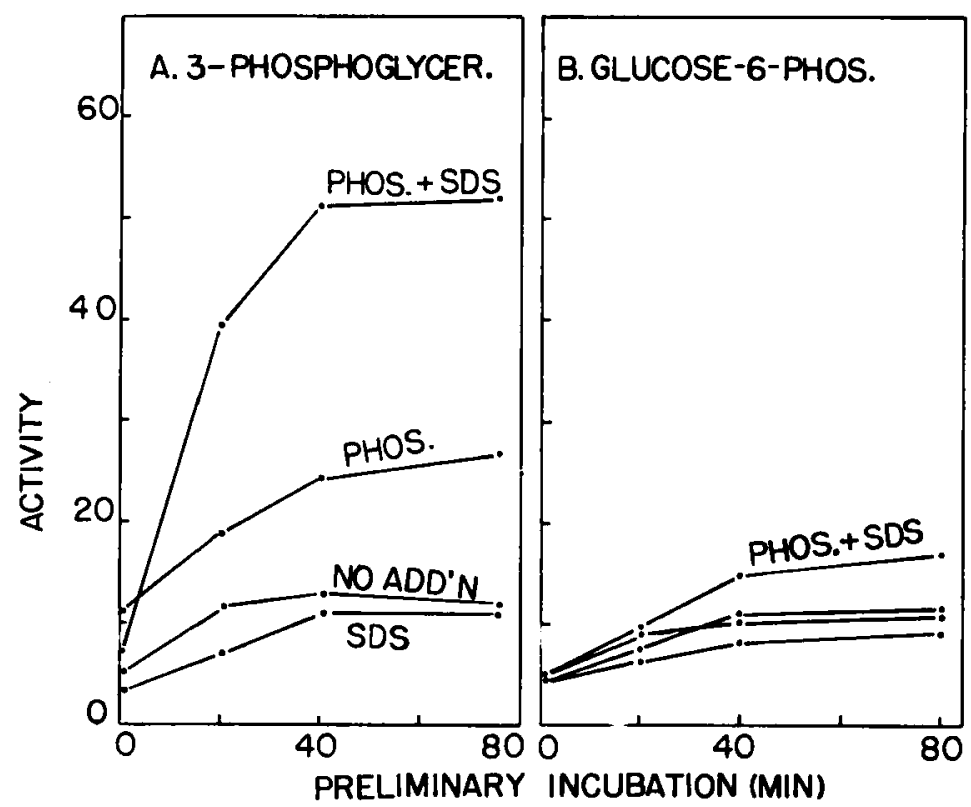

FIGURE 1. Effect of buffer composition and diethylstilbestrol disulfate (SDS) on the activation of resolved tyrosine transaminase by phosphorylase $b$ (phos.). During preliminary incubation at 37 degrees $C$., one sample contained (per $\mathrm{ml}$ incubation mixture) $310 \mu \mathrm{g}$ partially-purified tyrosine apotransaminase, $2.5 \mathrm{mg}$ freshly-prepared phosphorylase $b, 0.25$ $\mu$ moles SDS, and 0.02 mmoles "buffer," pH 7.6. Additional samples lacked either phosphorylase $b$, SDS, or both. (A) Preliminary incubation in $0.02 \mathrm{M}$ sodium 3-phosphoglycerate buffer. (B) Preliminary incubation in $0.02 \mathrm{M}$ sodium glucose-6-phosphate buffer. After the indicated preincubation periods, aliquots were removed and assayed for tyrosine transaminase activity, ${ }^{4}$ with and without added pyridoxal phosphate $\left(1.3 \times 10^{4} \mathrm{M}\right)$. Activity is expressed as $\mathrm{m} \mu \mathrm{moles}$ of $p$-hydroxyphenylpyruvate formed in 15 minutes.

The in vitro actions of steroid and nonsteroid effectors on pyridoxal enzymes might possibly be related to somewhat analogous actions of steroids and dietary factors in regulating the tissue levels of pyridoxal enzymes. The administration of steroids is known for example to cause the induction of a number of pyridoxal enzymes. $^{30-34}$ In those enzymes studied, the increases correlate well with increased enzyme concentration, as determined immunochemically. ${ }^{34,35}$

Singer and Mason reported ${ }^{20}$ that rat liver tyrosine transaminase activity was elevated following the administration of various anionic steroids and, at higher dosage levels, by a number of aromatic acids. Many of the same compounds stabilized that enzyme against irreversible inactivation in homogenates that were incubated at 37 degrees. These observations led to the suggestion that the stabilizing action may be causally related to the induction, one possibility being that these compounds also stabilize the somewhat labile enzyme in vivo, retarding the normal rapid degradation and thereby causing enzyme accumulation. Enzyme stabilization accounts to a large degree for the induction of tryptophan pyrrolase by injected tryptophan. ${ }^{36}$ The pyrrolase is induced by hydrocortisone also. ${ }^{37,38}$ These studies also indicated a difference in the sensitivity of the steroid and nonsteroid mediated inductions to inhibitors of protein and ribonucleic acid (RNA) synthesis, prompting the suggestion that the "hormonal" type of in- 
duction operated by increasing the rate of formation of the enzyme and the "substrate" type by decreasing the rate of degradation. ${ }^{36}$ Knox and Piras ${ }^{39}$ reported, however, that the "substrate" type also accelerated pyrrolase formation. Thus the possibility exists that the binding of small molecules to the enzyme may not only stabilize it in vivo but may in some way accelerate its rate of formation. Of course the latter action might also occur through an additional association with some other protein.

Because our in vitro model shows an interrelationship of steroid action, PLP binding, and enzyme stability, we are especially interested in in vivo relationships that appear to be analogous. The activities of a number of pyridoxal enzymes decline in the tissues in response to pyridoxine deficiency. ${ }^{40-44}$ In some cases, ${ }^{45,46}$ injection of excessive levels of pyridoxine caused within several hours a several-fold increase in enzyme levels. This action of pyridoxine on serine dehydrase $^{46}$ was accompanied by stabilization of the enzyme, presumably by its association with PLP. Other studies suggest that PLP may enhance the ability of steroids to increase or sustain enzyme levels in vivo. Eisenstein reported ${ }^{47}$ that the elevation of glutamate-alanine transaminase and glycogen levels following glucocorticoid injection was largely prevented by pyridoxine deficiency. Davis ${ }^{44}$ reported that pyridoxine deficiency caused a reduction in levels of tyrosine decarboxylase and 5-hydroxytryptophan decarboxylase in liver and kidney and that the amount of reduction was limited somewhat in animals receiving cortisone during development of the deficiency.

In addition to this and other ${ }^{48}$ evidence that steroids and dietary factors interact in increasing enzyme levels, several studies indicate that steroids may interfere with the actions of dietary factors in vivo. Dietrich and Shapiro ${ }^{49}$ observed that the administration of testosterone increased the sensitivity of several pyridoxal enzymes to antagonism by deoxypyridoxine. The decline in enzyme activity occurred more rapidly in animals treated with testosterone plus deoxypyridoxine than with deoxypyridoxine alone.

There are also indications as described elsewhere in this monograph that steroids interfere with the functions of PLP in tryptophan metabolism. Rose ${ }^{50}$ and Price, Brown and Thornton ${ }^{51}$ reported that the urinary excretion of tryptophan metabolites by normal women, following the ingestion of a test load of tryptophan, is modified considerably as a result of the use of birth-control pills (estrogen plus progestogen) or of estrogen alone. The excretory pattern resembled that occurring during pyridoxine deficiency. It assumed a nearly normal appearance when supplementary pyridoxine was given.

A similar pattern of urinary tryptophan metabolites occurs in pregnant women in response to the tryptophan load, ${ }^{52}$ and this pattern is also returned nearly to normal by pyridoxine supplementation. Brown and coworkers ${ }^{53}$ suggested that this apparent subclinical pyridoxine deficiency may be a result of the elevated blood levels of estrogen that occur during pregnancy. The discovery ${ }^{50,51}$ that administration of estrogen causes similar effects supports this suggestion. The mechanism described by Mason and Gullekson ${ }^{16}$ in which steroid metabolites interfere with PLP binding was suggested ${ }^{50,51}$ as a possible clue to the molecular basis of the in vivo actions.

The possibility that the in vitro interference of estrogens with PLP binding might explain the in vivo effects of estrogens on tryptophan metabolism prompted us to compare the effects of estrogen administration and pyridoxine deficiency on kynureninase and kynurenine transaminase levels in rat tissues. Results obtained with the transaminase will be presented. Earlier studies had shown ${ }^{54-56}$ that both 


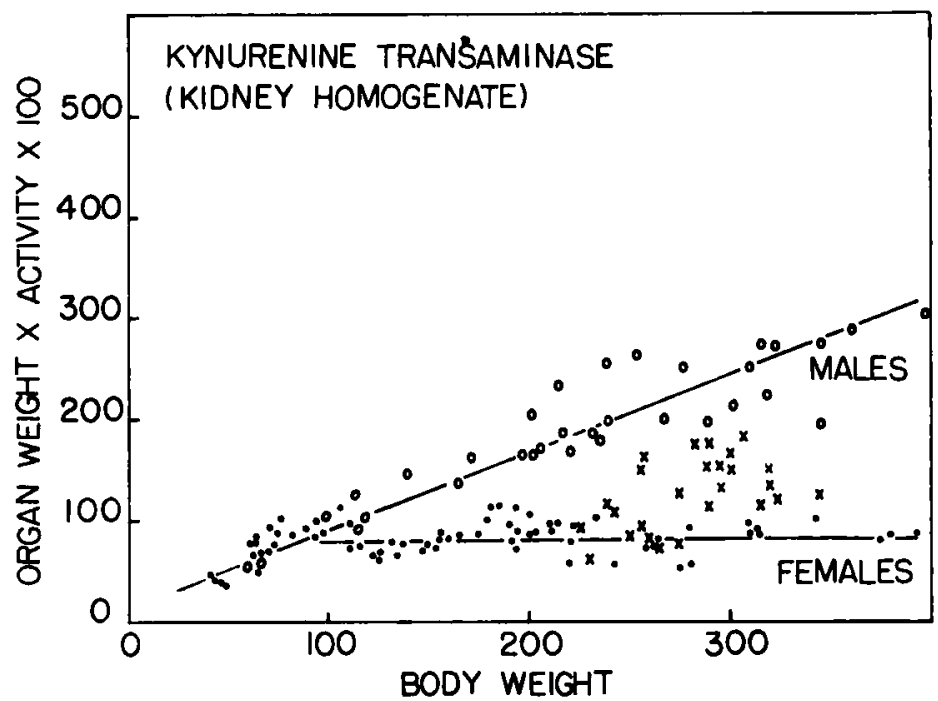

FIGURE 2. Kynurenine transaminase activity of kidney homogenates of male, female, and ovariectomized rats at various stages of growth. Enzyme activity was measured as described previously ${ }^{1}$ and was multiplied by the organ weight to give a value proportional to the activity of the entire organ. One group of females $(x)$ were ovariectomized and assayed as described in the test.

of these enzymes tended not only to become less completely saturated with PLP during deficiency but also to decline in amount, as judged by enzyme activities assayed $^{1,11}$ in the presence of saturating levels of PLP. Similar effects are to be expected if estrogens act simply by causing a relative deficiency of PLP or its redistribution.

Such action of estrogens on the enzyme levels was suggested by preliminary studies $^{57}$ which showed that there are marked sex differences in the renal kynurenine transaminase levels of adult rats (FIGURE 2). The kidneys of the males maintained higher levels of activity than those of the females during most of the growth period. After the females reached a body weight near $100 \mathrm{~g}$, the activities did not increase further as the organ weight increased. To test whether ovarian hormones were responsible for the sex differences, female rats weighing 175 to $200 \mathrm{~g}$ were ovariectomized, and after 1 to $21 / 2$ months, the kynurenine transaminase activities were assayed. That the ovaries have such a role is shown by the substantially higher enzyme levels resulting from ovariectomy (FIGURE 2). Such sex differences did not occur with the liver transaminase; ovariectomy had no significant effect on the levels (FIGURE 3 ).

Ogasawara and colleagues ${ }^{55}$ and $\mathrm{Ueda}^{56}$ reported that kynureninase activity is detectable only in the soluble fraction of rat liver, whereas the kynurenine transaminase is distributed predominantly in the mitochondrial fraction. On the other hand, about two-thirds of the kynurenine transaminase of kidney was in the soluble fraction. The supernatant transaminase was more completely depleted of PLP during dietary pyridoxine deficiency than the mitochondrial enzyme, and the apoenzyme levels in that fraction were also decreased more. These authors proposed that the increased excretion of xanthurenic acid commonly seen in pyridoxine deficiency may arise because the supernatant kynureninase 
and kynurenine transaminase are preferentially depleted, allowing the unreacted kynurenine greater exposure to the mitochondrial kynurenine hydroxylase and transaminase.

For studies of the estrogen effects on kynurenine transaminase, albino rats (Spartan Farms, Plymouth, Mich.) were purchased at $100 \pm 5 \mathrm{~g}$ body weight and were maintained on Rockland rat diet ad lib. One-half of a group of male rats were given drinking water containing $0.5 \mu \mathrm{g}$ diethylstilbestrol per $\mathrm{ml}$. The control male group and a similar female group were given untreated drinking water. After 10 to 30 days of such treatment, the rats were killed by exsanguination. Experiments were begun routinely at 9:00 a.m. to minimize the effects of any diurnal variations. The liver and both kidneys were removed immediately and placed on ice. The kidneys were weighed and placed in a cold homogenizer, to which was then added $4 \mathrm{ml} 0.25 \mathrm{M}$ sucrose per $\mathrm{g}$ tissue (buffered at pH 7.3 with $6 \mathrm{mM} \alpha$-ketoglutarate). The liver was weighed, and a portion equal to the weight of both kidneys was transferred to another homogenizer, along with the same volume of sucrose- $\alpha$-ketoglutarate solution. Both tissues were homogenized in the cold. The homogenates were then centrifuged at $30,000 \mathrm{~g}$ for 20 minutes. The supernatant fractions were decanted and stored on ice. The residues were suspended in the original volume of sucrose- $\alpha$-ketoglutarate solution, homogenized, and centrifuged at $10,000 \mathrm{~g}$ for 20 minutes. The supernates were decanted and discarded. The washed residues were suspended and homogenized as before and were then centrifuged gently (about $750-1,000 \mathrm{rpm}$ ) for 10 minutes. The supernatant fraction (containing the mitochondria) was decanted and stored. Aliquots $(0.1 \mathrm{ml})$ of each of the two "supernate" and the two "mitochondria" fractions were assayed, with and without added PLP. With these assay conditions, the liver supernate had very little activity and data concerning that fraction are not presented.

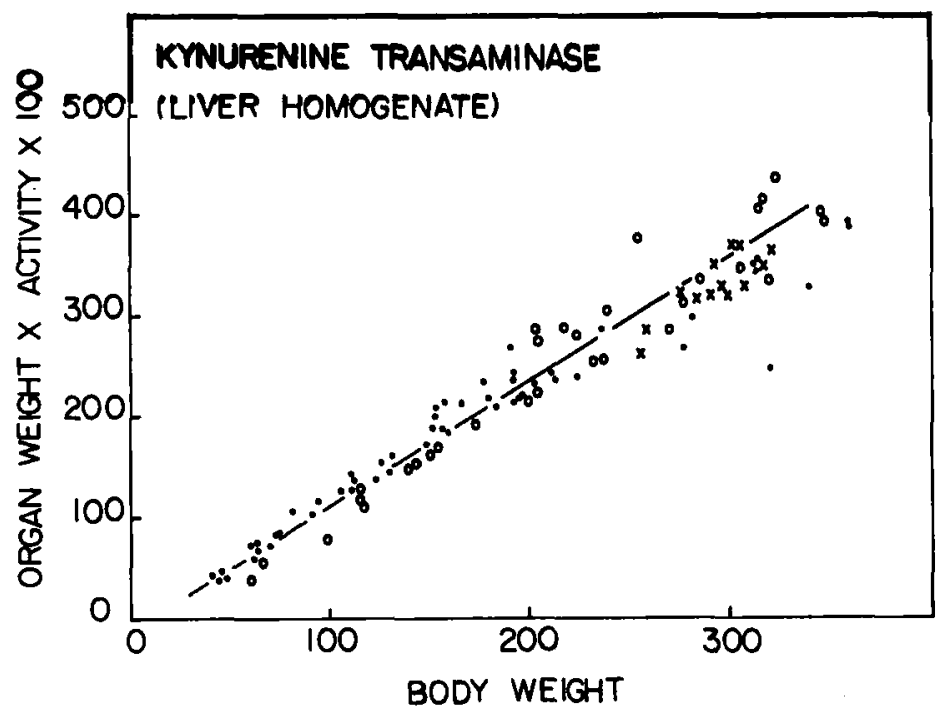

Figure 3. Kynurenine transaminase activity of liver homogenates of male, female, and ovariectomized rats at various stages of growth. Enzyme activity of the organ is expressed as in Figure 2 for males $(0)$, females (*), and ovariectomized females $(x)$. 


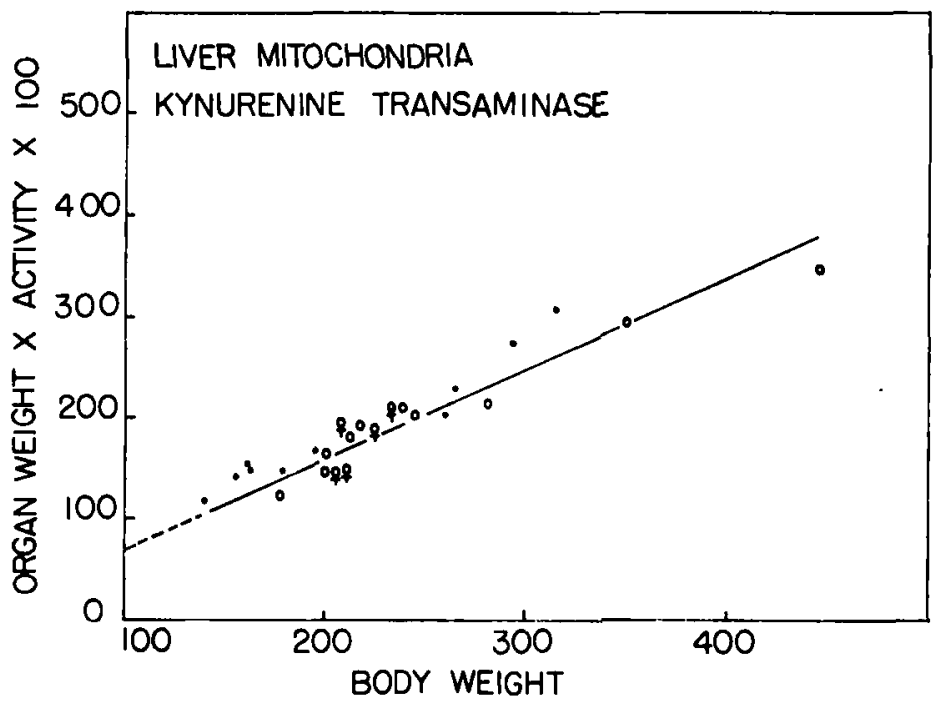

FIgURE 4. Kynurenine transaminase activity of a mitochondrial fraction of the liver of male, female, and estrogen-treated male rats at various stages of growth. Treatment and tissue fractionation are described in the text. Enzyme activity is expressed as in FIGURE 2 for males $(0)$, females $(q)$, and estrogen-treated males $(\bullet)$.

In FIGURE 4, it is seen that the mitochondrial fraction of liver reflects the pattern of the whole homogenate (FIGURE 3), i.e., no significant sex difference was found, and estrogen treatment was without effect. The mitochondrial fraction of kidney, however, shows a distinctly lower activity for the estrogen-treated males (FIGURE 5). Females, treated similarly to the male controls, showed a similar decrease. Similar but less distinct decreases for the kidney supernate transaminase was observed (FIGURE 6), however, the range of variation was much greater for that fraction, causing some overlap.

TABLE 1 shows the "percent saturation" of the transaminase with PLP in each of the three fractions for the groups described in FIGURES 4, 5, and 6 . This value for the kidney mitochondria, determined by dividing the activity obtained with added PLP into the value obtained without added PLP, was significantly higher in the male rats than in either the females or estrogen-treated males. A significant difference was also found with the kidney supernatant fraction, but in the opposite direction-the value was higher for the females and estrogen-treated males than for the control males. The differences found between males and estrogen-treated males with the liver mitochondria are also significant.

Since these effects of estrogen administration differed somewhat from the reported effects of pyridoxine deficiency, ${ }^{55,56}$ we have reexamined the effects of the deficiency, using methods similar to those described above for studying the effects of estrogens. Male rats, purchased at $100 \pm 5 \mathrm{~g}$ body weight were placed on a pelleted pyridoxine-deficient diet (Nutritional Biochemicals Corp.). Half of the rats were given pyridoxine $\mathrm{HCl}$ at a level of $5 \mu \mathrm{g}$ per $\mathrm{ml}$ in the drinking water. After 10 to 30 days, they were sacrificed as described above and the tissues were fractionated and assayed as before. The results are plotted as before (FIGURES $7,8,9$ ) and are compared with the trends found for females and normal 


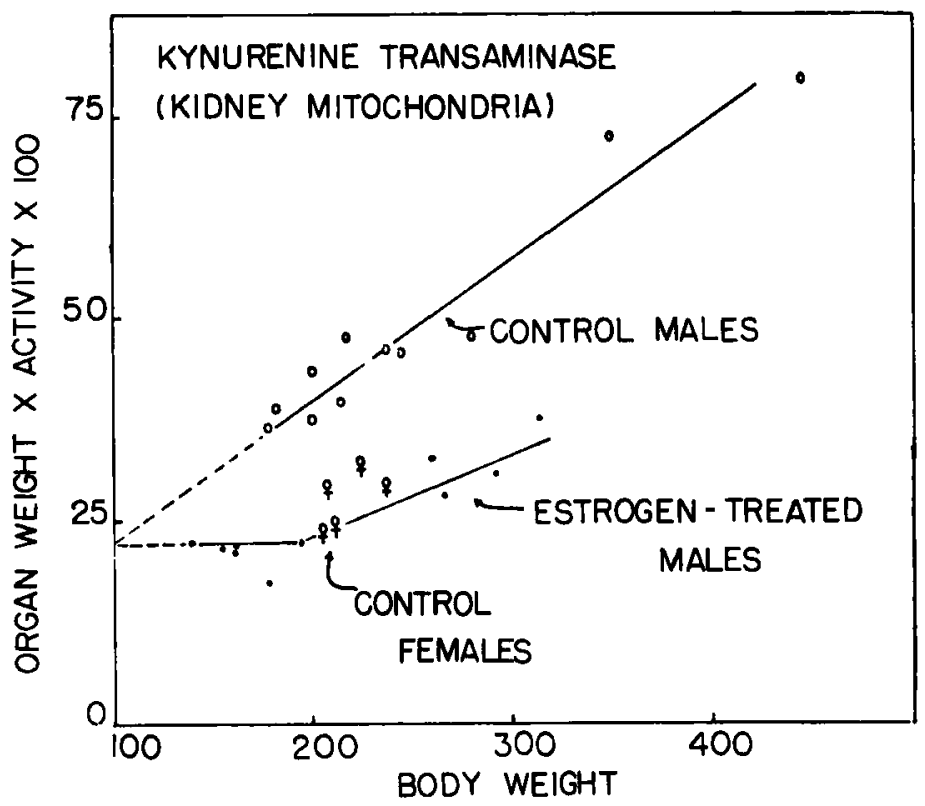

Figure 5. Kynurenine transaminase activity of a mitochondrial fraction of kidney of male, female, and estrogen-treated male rats at various stages of growth. Treatment and tissue fractionation are described in the text. Enzyme activity is expressed as in FIGURE 2 for males $(0)$, females ( $q$ ), and estrogen-treated males $(\bullet)$.

and estrogen-treated males (FIGURES $4,5,6$ ). The "percent saturation" values are shown in TABLE 2. The results show the expected decline of activity and "percent saturation," with much greater changes in the supernatant fraction as described by Ueda and by Ogasawara and coworkers.

\section{Discussion}

Some similarities and some remarkable differences have been detected in these comparisons of the effects of estrogen treatment and dietary pyridoxine deficiency on renal and hepatic kynurenine transaminase. Both treatments caused a decline in the kidney supernatant transaminase levels, but the decline was associated in the dietary deficiency with decreased "percent saturation" with PLP as compared with controls, whereas estrogen-treatment caused increased "percent saturation" as compared with untreated controls. The development of the renal mitochondrial transaminase was relatively undisturbed by pyridoxine deficiency but strongly retarded by estrogen treatment. In both conditions the "percent saturation" values were only slightly depressed in this fraction. The enzyme levels and percent saturation values of the estrogen-treated males were remarkably similar to those of normal females.

Pyridoxal enzymes that are influenced by steroids are generally also sensitive to dietary levels of protein. The substantially lower transaminase levels found with the controls fed the deficient diet plus pyridoxine as compared with animals on the "complete" pellet diet is probably attributable to dietary factors other than the level of pyridoxine, since increasing the pyridoxine level did not increase 


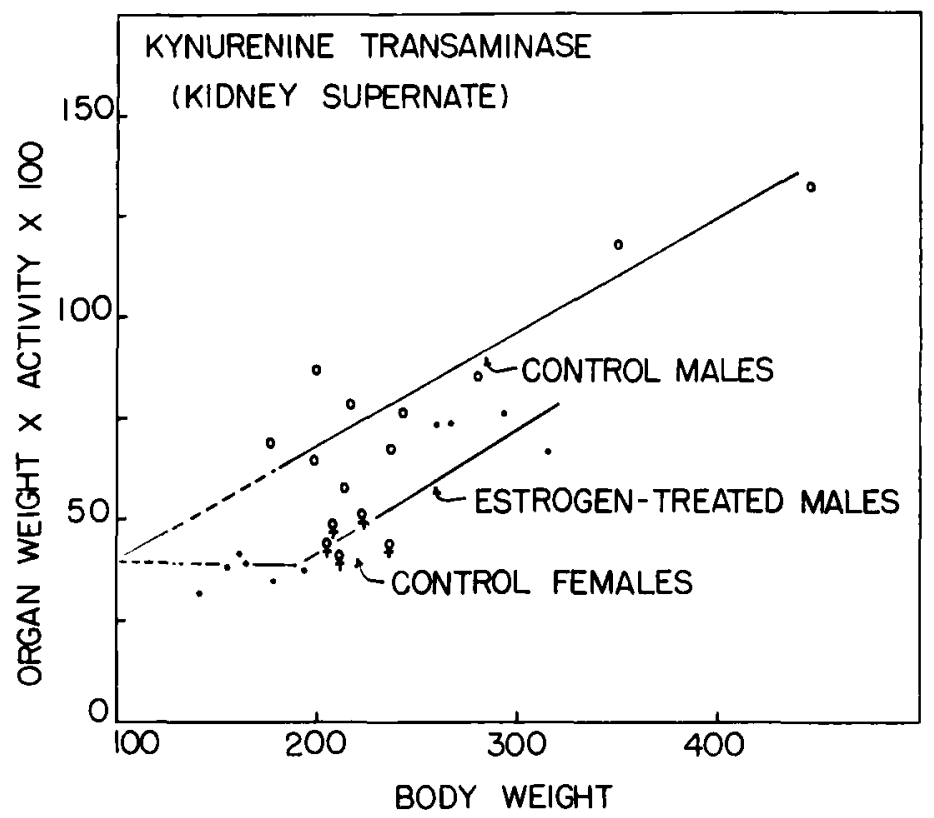

FIGURE 6. Kynurenine transaminase activity of a supernatant fraction of kidney of male, female, and estrogen-treated male rats at various stages of growth. Treatment and tissue fractionation are described in the text. Enzyme activity is expressed as in Figure 2 for males $(0)$, females ( $q)$, and estrogen-treated males $(\bullet)$.

TABLE 1

Percent Saturation* of Liver and Kidney Kynurenine Transaminase With Pyridoxal Phosphate (PLP)

\begin{tabular}{lcccc}
\hline & & \multicolumn{2}{c}{ Percent Saturation with PLP } \\
\cline { 2 - 5 } \multicolumn{1}{c}{ Treatment } & $\begin{array}{c}\text { No. of } \\
\text { Rats }\end{array}$ & $\begin{array}{c}\text { Kidney } \\
\text { Mitochondria }\end{array}$ & $\begin{array}{c}\text { Kidney } \\
\text { Supernate }\end{array}$ & $\begin{array}{c}\text { Liver } \\
\text { Mitochondria }\end{array}$ \\
\hline Males & 7 & $68.9 \pm 0.6$ & $45.6 \pm 1.7$ & $53.8 \pm 2.4$ \\
Females & 5 & $62.9 \pm 1.6 \dagger$ & $51.3 \pm 1.9 \dagger$ & $54.3 \pm 2.0$ \\
Estrogen-treated males & 6 & $61.9 \pm 1.4 \dagger$ & $50.9 \pm 2.1 \dagger$ & $58.2 \pm 3.4 \dagger$ \\
\hline
\end{tabular}

* Percent saturation with PLP $=100$ (activity without PLP/activity with PLP). Treatment fractionation, and assay are described in the text.

$\dagger$ Mean value \pm standard deviation. Difference from value for males is statistically significant $(\mathrm{p}<0.01)$.

the enzyme level. Additional studies of the influence of dietary variations are in progress. At present it appears (FIGURE 8 ) that the renal mitochondrial transaminase is relatively insensitive to the dietary factors that regulate the renal supernatant and hepatic mitochondrial transaminase. The relatively greater sensitivity of the renal supernatant transaminase to dietary variations suggests that the levels of enzyme in that fraction may fluctuate with short-term variations in nutritional status, perhaps explaining the much greater range of variation of the enzyme levels for that fraction (FIGURE 6).

Since the present data provide evidence of a redistribution of PLP during treat- 


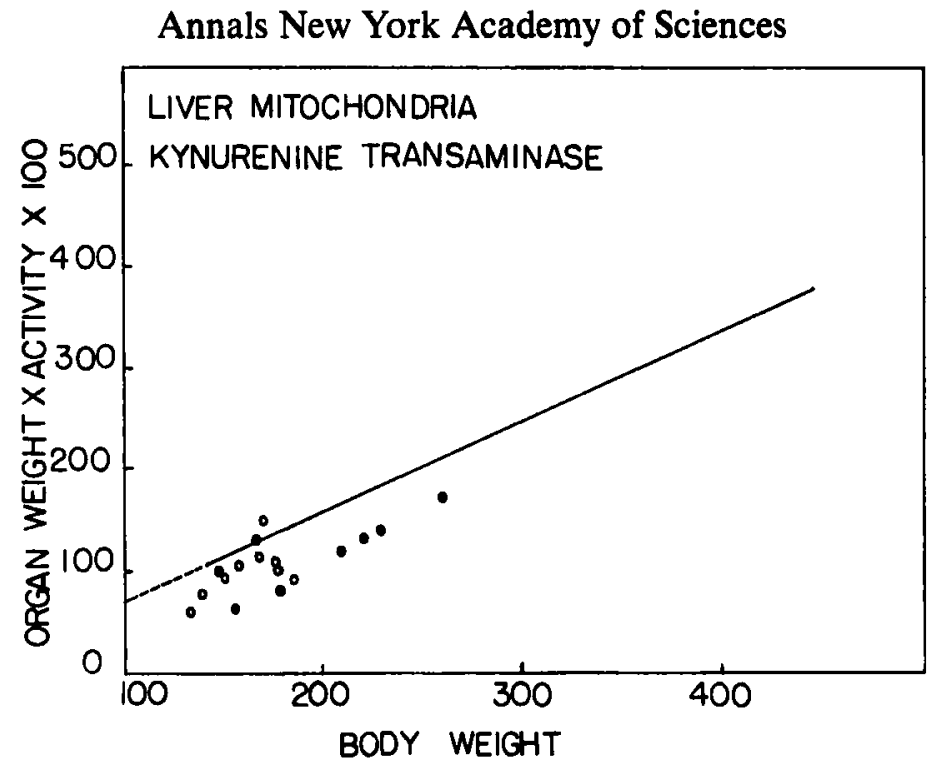

FIGURE 7. Kynurenine transaminase activity of a mitochondrial fraction of liver of pyridoxine-deficient and control rats at various stages of growth. Treatment and tissue fractionation are described in the text. Enzyme activity is expressed as in FIGURE 2 for pyridoxine-deficient $(0)$ and control $(\bullet)$ male rats. The line is derived from FIGURE 4, for comparison with the effects of estrogen-treatment.

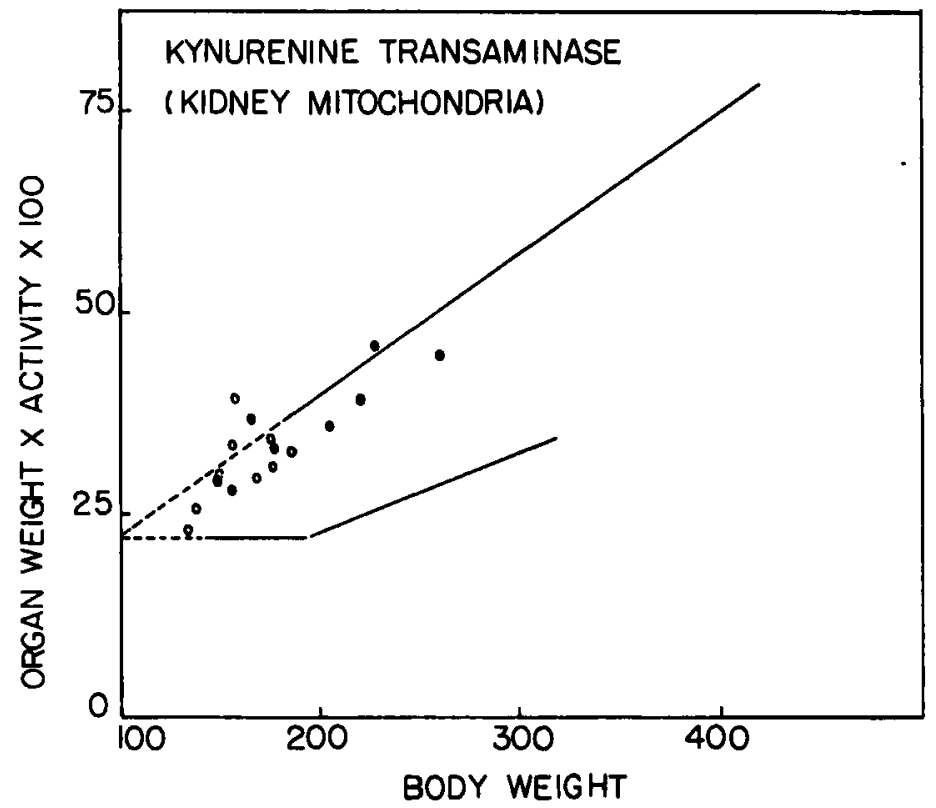

FIGUke 8. Kynurenine transaminase activity of a mitochondrial fraction of kidney of pyridoxine-deficient and control rats at various stages of growth. Treatment and tissue fractionation are described in the text. Enzyme activity is expressed as in FIGURE 2, for pyridoxinedeficient $(0)$ and control $(\bullet)$ male rats. The lines are derived from Figure 5, for comparison with the effects of estrogen treatment. 


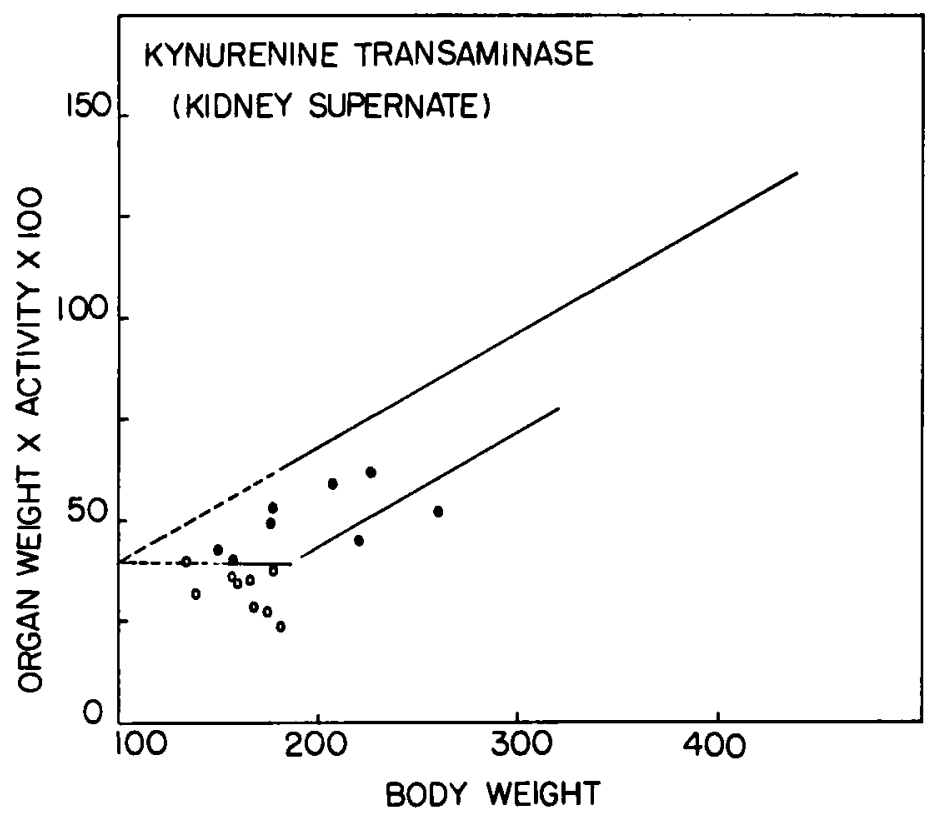

FIgURE 9. Kynurenine transaminase activity of a supernatant fraction of kidney of pyridoxine-deficient and control rats at various stages of growth. Treatment and tissue fractionation are as described in the text. Enzyme activity is expressed as in FIGURE 2, for pyridoxine-deficient $(0)$ and control $(\bullet)$ male rats. The lines are derived from FIGURE 5 for comparison with the effects of estrogen treatment.

TABLB 2

Percent Saturation* of Liver and Kidney Kynurenine Transaminase with Pyridoxal. Phosphate (PLP)

\begin{tabular}{ccccc}
\hline \hline Treatment & $\begin{array}{c}\text { No. of } \\
\text { Rats }\end{array}$ & $\begin{array}{c}\text { Kidney } \\
\text { Mitochondria }\end{array}$ & $\begin{array}{c}\text { Percent Saturation with PLP } \\
\text { Kidney } \\
\text { Supernate }\end{array}$ & Mitochondria \\
\hline $\begin{array}{c}\text { B }_{\sigma} \text {-Def. diet } \\
\begin{array}{c}\text { B }_{\text {o }} \text {-Def. diet } \\
\text { plus pyridoxine }\end{array}\end{array}$ & 8 & $61.1 \pm 5.4$ & $26.4 \pm 8.4$ & $47.0 \pm 7.8$ \\
\hline \hline
\end{tabular}

- Percent saturation with PLP $=100$ (activity without PLP/activity with PLP). Treatment, fractionation, and assay are described in the text.

$\dagger$ Mean value \pm standard deviation. Difference from pyridoxine-deficient group is statistically significant $(\mathrm{p}<0.01$ ). Pyridoxine dosage was increased to $15 \mu \mathrm{g} / \mathrm{ml}$ for three of this group after four weeks on $5 \mu \mathrm{s} / \mathrm{ml}$. No increases in percent saturation values were observed.

ment with estrogen, it is consistent with the idea that estrogens influence the transaminase in vivo in a fashion similar to that observed in vitro. However, estrogen administration does not cause the same pattern of changes as that resulting from dietary pyridoxine deficiency. Because of the very complex response to both the dietary and hormonal treatment, continued investigation will be required to evaluate the relation of the responses to the in vitro model and their relevance to the actions of estrogens in human subjects. 


\section{SUMMARY}

Earlier studies of the effects of steroid and nonsteroid metabolites on pyridoxal enzymes were reviewed. These studies indicate that conjugated steroids can cooperate with or oppose the actions of specific nonsteroid effectors in determining enzyme conformation, activity, stability, and coenzyme binding.

Evidence is presented that these actions of steroid and nonsteroid metabolites can cause a redistribution of PLP between apoenzymes. The possibility is considered that similar actions may account for the ability of estrogens to cause changes in tryptophan metabolism resembling those occurring during pyridoxine deficiency. The effect of estrogen-treatment and of dietary pyridoxine deficiency on the kynurenine transaminase levels in liver and kidneys of male rats were compared. Pyridoxine deficiency resulted in a moderate decline of the percent saturation of the renal supernatant enzyme with pyridoxal phosphate but also caused an apparent decline in the apoenzyme levels. Treatment of male rats with estrogen caused similar changes in apoenzyme levels but increased the "percent saturation" values. The renal mitochondrial apotransaminase levels decreased only slightly during pyridoxine deficiency but were markedly decreased by estrogen-treatment. Both types of treatment resulted in relatively small decreases in the "percent saturation" values for that fraction. Female rats displayed very similar apoenzyme levels and "percent saturation" values to those of estrogentreated males.

The results were interpreted as consistent with the idea that the estrogens influence kynurenine transaminase in vivo in a fashion somewhat similar to that observed in vitro but also as demonstrating that they do not cause the same pattern of change in apoenzyme levels and pyridoxal phosphate distribution as the dietary pyridoxine deficiency.

\section{REFERENCES}

1. Mason, M. 1957. J. Biol. Chem. 227: 61 .

2. Scardi, V., P. Scotto, M. laccarino \& E. Scarano, 1963. Biochem. J. 88: 172.

3. TORChINSKY, YU A. 1963. Biokhimiia 28: 731.

4. Hayashi, S. I., D. Granner \& G. M. Tomkins. 1967. J. Biol. Chem. 242: 3998.

5. Jenkins, W. T. \& I. W. Sizer. 1957. J. Amer. Chem. Soc. 79: 2655.

6. Jenkins, W. T. \& I. W. Sizer. 1960. J. Biol. Chem. 235: 620.

7. Novogrodsky, A. \& A. Meister. 1964. J. Biol. Chem. 239: 879.

8. SchirCh, L. \& W. T. Jenkins. 1964. J. Biol. Chem. 239: 3797.

9. Illingsworth, B., H. S. Jansz, D. H. Brown \& C. F. Cori. 1958. Proc. Nat. Acad. Sci. 44: 1180 .

10. Kent, A. B., A. G. Krebs \& E. H. Fischer. 1958. J. Biol. Chem. $232: 549$.

11. MAson, M. 1959. J. Biol. Chem. 234: 2770.

12. Jenkins, W. T., D. A. Yphantis \& I. W. Sizer. 1959. J. Biol. Chem. $234: 51$.

13. Jenkins, W. T. \& L. D'ARI. 1966 . J. Biol. Chem. 241: 5667.

14. Singer, S., J. Ford, L. SCHIRCh \& M. Mason. 1366. Life Sci. 5: 837.

15. Mason, M. \& E. Gullekson. 1959. J. Amer. Chem. Soc. 81: 1517.

16. Mason, M. \& E. Gullekson. 1960. J. Biol. Chem. 235: 1312.

17. MASON, M. \& L. Schirch. 1961. Fed. Proc. 20: 200.

18. Scardi, V., M. Iaccorino \& E. Scarano. 1963. Biochem. J. 83: 413.

19. Ford, J. \& M. Mason. 1968. Proc. Nat. Acad. Sci. 59: 980.

20. SinGER, S. \& M. MASON. 1967. Biochim. Biophys. Acta 146: 452.

21. Oelkers, W. \& W. Nolten. 1964. Hoppe Seyler. Z. Physiol. Chem. 338: 105.

22. Yielding, K. L. \& G. M. Tomkins. 1960. Proc. Nat. Acad. Sci. 46: 1483.

23. Willman, K. \& M. Pulkkinen. 1967. J. Eur. Steroids 2: 77.

24. Wada, H. \& E. E. SNell. 1962. J. Biol. Chem. 237: 127.

25. Wu, H. L. C. \& M. Mason. 1964. J. Biol. Chem. 239: 1492.

26. Leybold, K. \& HJ. Staudinger. 1963. Biochem. Z. 337: 320. 
27. WU, H. L. C. \& M. Mason. 1965. Steroids $5: 45$.

28. WU, H. L. C. \& M. MASON. (Unpublished data.)

29. Fischer, E. H., A. B. Kent, E. R. Snyder \& E. G. Krebs. 1958. J. Amer. Chem. Soc. 80: 2906.

30. LIN, E. C. C. \& W. E. KNox, 1957. Biochim. Biophys. Acta 26: 85.

31. Kenney, F. T. \& R. M. Flora. 1961. J. Biol. Chem. 236: 2699.

32. Scow, R. O. \& M. A. Grear. 1955. Endocrinology 56: 590.

33. Harris, G. W. \& S. W. Woods, 1957. Ciba Foundation Colloquia on Endocrinology 10: 1 .

34. Fiegelson, P. \& O. Greengard. 1962. J. Biol. Chem. 237: 3714.

35. KenNeY, F. T. 1962. J. Biol. Chem. 237: 1610.

36. Shimke, R. T., E. W. SWeeney \& C. M. Berlin. 1965. J. Biol. Chem. $240: 322$.

37. Civen, M. \& W. E. KNox. 1959. J. Biol. Chem. 234: 1787.

38. Greengard, O. \& P. Fiegelson. 1961. Nature 190: 446.

39. Knox, W. E. \& M. M. Piras. 1967. J. Biol. Chem. 242: 2959.

40. Mason, M. \& C. P. Berg. 1952. J. Biol. Chem. 195: 515.

41. HOPE, D. B. 1955. Biochem. J. 59: 497.

42. Greengard, O. 1963. Advances Enzyme Regulat. 2: 277.

43. Chatagner, F. \& C. Durien-Trautmann. 1965. Nature 207: 1390.

44. Davis, V. E. 1963. Endocrinol. 72: 33.

45. Greengard, O. \& M. Gordon. 1963. J. Biol. Chem. 238: 3708.

46. Khalrallah, E. A. \& H. C. Pitot. Symposium on Pyridoxal Enzymes, Nagoya, 1967. p. 159. Maruzen Co., Lid., Tokyo. 1968.

47. Eisenstein, A. B. 1960. Endocrinology 67: 97.

48. Pitot, H. C., Y. S. Cho, C. Lamar, Jr. \& C. Peraino. 1965. J. Cell. Comp. Physiol. 66: 163 .

49. Dietrich, L. S. \& D. M. Shapiro. 1955. Cancer Res. 15: 133.

50. Rose, D. P. 1966. Clin. Sci. 31: 265.

51. Price, J. M., R. R. Brown \& M. J. Thornton. 1967. Amer. J. Clin. Nutr. $20: 452$.

52. Wachstein, M. \& A. Gudaitas. 1953. J. Lab. Clin. Med. 42: 98.

53. Brown, R. R., M. J. Thornton \& J. M. Price. 1961. J. Clin. Invest. $40: 617$.

54. Mason, M. \& C. P. Berg. 1952. J. Biol. Chem. 195: 515.

55. Ogasawara, N., Y. Hagino \& Y. Kotake. 1962. J. Biochem. 52: 162.

56. UedA, T. 1967. Nagoya J. Med. Sci. 30: 259.

57. Mason, M. \& E. Gullekson. 1960. Fed. Proc. 19: 170. 